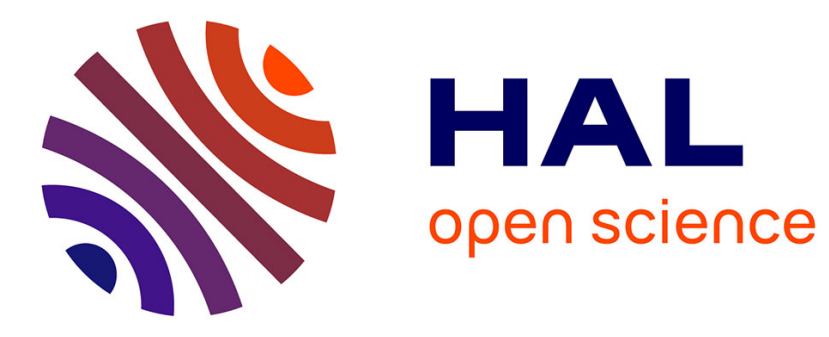

\title{
Molecular dynamics in electrospun amorphous plasticized polylactide fibers
}

X Monnier, N. Delpouve, N Basson, A Guinault, S Domenek, A Saiter, P.E Mallon, E Dargent

\section{- To cite this version:}

X Monnier, N. Delpouve, N Basson, A Guinault, S Domenek, et al.. Molecular dynamics in electrospun amorphous plasticized polylactide fibers. Polymer, 2015, 73, pp.68-78. 10.1016/j.polymer.2015.07.047 . hal-01195805

\section{HAL Id: hal-01195805 \\ https://hal.science/hal-01195805}

Submitted on 8 Sep 2015

HAL is a multi-disciplinary open access archive for the deposit and dissemination of scientific research documents, whether they are published or not. The documents may come from teaching and research institutions in France or abroad, or from public or private research centers.
L'archive ouverte pluridisciplinaire HAL, est destinée au dépôt et à la diffusion de documents scientifiques de niveau recherche, publiés ou non, émanant des établissements d'enseignement et de recherche français ou étrangers, des laboratoires publics ou privés. 


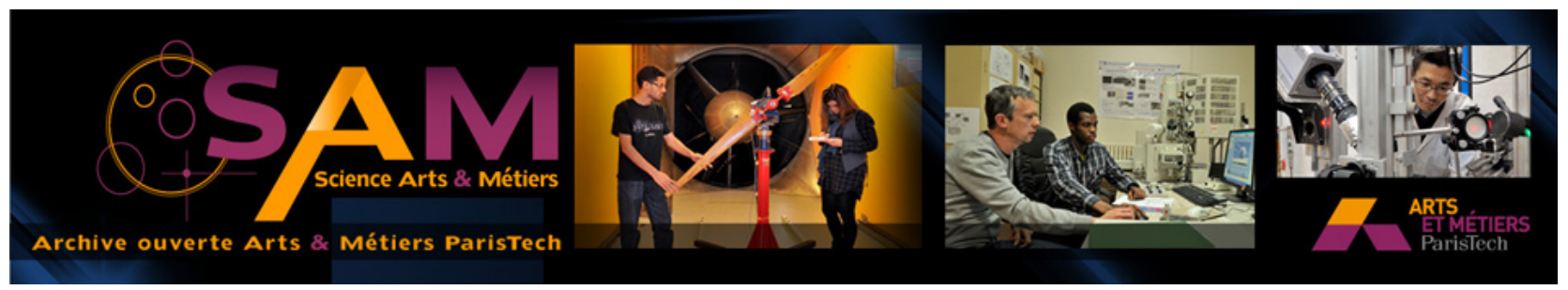

\section{Science Arts \& Métiers (SAM)}

is an open access repository that collects the work of Arts et Métiers ParisTech researchers and makes it freely available over the web where possible.

This is an author-deposited version published in: http://sam.ensam.eu

Handle ID: .http://hdl.handle.net/10985/9951

\section{To cite this version :}

X MONNIER, N DELPOUVE, N BASSON, A GUINAULT, S DOMENEK, A SAITER, P.E MALLON, E DARGENT - Molecular dynamics in electrospun amorphous plasticized polylactide fibers - Polymer - Vol. 73, p.68-78 - 2015 


\title{
Molecular dynamics in electrospun amorphous plasticized polylactide fibers
}

\author{
X. Monnier ${ }^{\mathrm{a}, \mathrm{d}}$, N. Delpouve ${ }^{\mathrm{a},{ }^{*},}$, N. Basson ${ }^{\mathrm{d}}$, A. Guinault ${ }^{\mathrm{b}}$, S. Domenek ${ }^{\mathrm{c}}$, A. Saiter ${ }^{\mathrm{a}}$, \\ P.E. Mallon ${ }^{\mathrm{d}}$, E. Dargent ${ }^{\mathrm{a}}$ \\ a AMME-LECAP EA 4528 International Lab., Av. de l'Université, BP12, Normandie Univ. France, Université and INSA Rouen, 76801 St Etienne de Rouvray, \\ France \\ ${ }^{\mathrm{b}}$ CNAM, Laboratoire PIMM, UMR 8006, 151 Boulevard de l'Hôpital, 75013 Paris, France \\ ' AgroParisTech, UMR1145 Ingénierie Procédés Aliments, 1 Avenue des Olympiades, 91300 Massy, France \\ d Department of Chemistry and Polymer Science, University of Stellenbosch, Private Bag X1, 7602 Matieland, South Africa
}

Keywords:

Nanofibers

PLA

Amorphous phase

\begin{abstract}
A B S T R A C T
The molecular dynamics in the amorphous phase of electrospun fibers of polylactide (PLA) has been investigated using the cooperative rearranging region concept. An unusual and significant increase of the cooperativity length at the glass transition induced by the electrospinning has been observed. This behavior is attributed to the singularity of the amorphous phase organization. Electrospun PLA fibers rearrange in a pre-ordered metastable state which is characterized by highly oriented but non-crystalline polymer chains, and the presence of highly cohesive mesophase which plays the role of an anchoring point in the amorphous phase. The successful processing of electrospun fibers of plasticized polylactide is also demonstrated. It is shown that the plasticizer remains in the polymer matrix of the nanofiber after electrospinning. When PLA is plasticized, the loosening of the macromolecules prevails over the preferential orientation of the chains; therefore no mesophase is formed during the electrospinning and the cooperativity length remains the same. When the content of plasticizer increases, the inter-chain characteristic distances estimated from wide angle X-ray scattering (WAXS) are redistributed, suggesting a change in the level of interactions between macromolecules. It is assumed that the resulting decrease of the cooperativity length is driven by the progressive reduction of the number of inter-chain weak bonds. It is shown that in a non-confined environment, the number of structural entities involved in the alpha relaxation is strongly dependent on the level of physical interactions in the amorphous phase.
\end{abstract}

\section{Introduction}

In the theory of Adam and Gibbs [1], the relaxation process related to the glass transition is cooperative, and the motion of a structural unit is only possible if a given number of neighboring units are also in motion. Among the different models used to estimate the size of the Cooperative Rearranging Region (CRR) or cooperativity length, is the thermodynamic approach proposed by Donth [2] which relates the CRR to the dynamic heterogeneity deduced from the temperature fluctuation associated with the glass transition. This approach provides a picture of the relaxation

\footnotetext{
* Corresponding author.

E-mail address: nicolas.delpouve1@univ-rouen.fr (N. Delpouve).
}

time at the glass transition which is directly observable through calorimetric measurements [3]. According to this approach [2], the cooperativity volume $\xi_{T \alpha}^{3}$ at the dynamic glass transition temperature $T_{\alpha}$ can be estimated from the following equation:

$\xi_{T \alpha}^{3}=\frac{\left(1 / C_{p}\right)_{\text {Glass }}-\left(1 / C_{p}\right)_{\text {Liquid }}}{\rho(\delta T)^{2}} k_{B} T_{\alpha}^{2}$

With $k_{B}$ the Boltzmann constant, $\delta T$ the average temperature fluctuation related to the dynamic glass transition of a CRR, $\rho$ the density, and $C_{p}$ the heat capacity at constant pressure. Two causes for cooperativity changes have been observed so far. The first relates to changes in thermodynamic variables such as temperature, and the second to structural modifications of the material. In the first case, it is well known that the cooperativity length increases 
when the temperature decreases from the crossover temperature for which the cooperativity arises to the glass transition temperature [4-6]. In the second case, the approach of Donth has widely been used to investigate the decrease of cooperativity for two kinds of structural hindrances namely external and internal hindrances. External hindrances are related to geometrical restrictions like the confinement between nanolayers $[7,8]$ or the addition of additives such as fillers $[9,10]$ or plasticizer [11]. On the other hand, internal hindrances are related to the materials itself, in other words its microstructural modifications such as spherulitic crystallization $[12,13]$ or orientation/crystallization of the amorphous phase induced by drawing $[5,14]$.

In the last decade, the growing interest for polylactide (PLA) as a promising substitute to petroleum issued polymers has led researchers to investigate how its macroscopic properties could be tailored by controlling its microstructure. Because of the strong dependence of PLA macroscopic properties on its microstructure [15] and molecular dynamics [16], the cooperativity of the alpha relaxation process has been particularly investigated when the relaxation dynamics of the amorphous phase are modified by orientation [17], crystallization [13], or even plasticization [11]. However, the impact of several microstructural modifications on the amorphous phase dynamics remains unknown. For example, as illustrated by several authors [18-20], given conditions for drawing or thermal crystallization may induce the development of an intermediate ordering structure called a mesophase which prefigures the crystallization. The observation of the mesophase is generally reported for semi-crystalline materials [18-22] for which crystals strongly impact the investigation of the molecular mobility. Consequently, no study deals with the impact alone of the mesophase on the molecular dynamics of the amorphous phase. One of the challenges to carry out such a study lies in obtaining a unique microstructure where the mesophase is only dispersed in the oriented amorphous phase, without the presence of crystals. In the current study, we propose to electrospin polylactide (PLA) fibers to create this specific microstructure. Electrospinning is a simple technique to implement in order to produce polymer fibers with diameters ranging from the micro-to the nanoscale [23-25]. The technique has emerged as a useful technique to produce micro- and nano-fibers that have found wide applications in fields such as tissue engineering [26], biomedical [27], filtration [28], or electronic [29]. Despite the simplicity of the technique, many factors influence the fiber morphology including the solution flow rate, the distance between the syringe and the collector, solution concentration and the spinning voltage among others. In addition, very complex processes are involved that influences the fiber structure including the very rapid solvent evaporation as well as the mechanical and electrical forces which induce an orientation of the macromolecular chains along the fiber axis [24]. For these reasons, electrospinning can lead to complicated internal microstructures and high contents of mesophase [30]. Zong et al. [31] initially reported that electrospun fibers of polylactide (PLA) exhibit highly oriented chains although they are non-crystalline. Recently Ma et al. [32] confirmed this result by showing that the electrospinning carried on free-end fibers of PLA leads to the formation of an original microstructure where the amorphous phase is oriented with evidence of a mesophase but without the formation of any crystals. In the current study, we report for the first time on the cooperativity lengths obtained for as-spun fibers of polylactide using Donth's approach. We use the electrospinning technique in order to avoid the effects related to the confinement of the amorphous phase by crystals, similar to what is observed during drawing. The process has been designed to prevent any formation of the crystalline phase during the fiber formation.

As is well known, the applications for neat PLA are usually compromised due to its inherent brittleness [33]. Thus, plasticizers are often added to PLA in order to improve its mechanical properties. Acetyl Tributyl Citrate (ATBC) considered here, is among the most widely used plasticizers [33,34]. In this study, we report for the first time the electrospinning of plasticized PLA. Here, the goal is to observe if the internal modifications related to the mesophase still exist when ATBC is added as a plasticizer. It will allow another aspect of the impact of microstructural modifications on the amorphous phase dynamics to be depicted from the combination of both internal/external hindrances. Two series of samples have been analyzed: as-spun plasticized fibers and bulk plasticized PLA. Finally it is of interest to determine if the plasticizer remains inside the fibers after the electrospinning process and thus still acts as a plasticizer for the polymer nanofibers.

\section{Experimental}

\subsection{Materials}

Semi-crystalline PLA pellets (grade 4042D) were provided by Natureworks. The content of L-lactide and D-lactide were about $96 \%$ and $4 \%$ respectively. The number-average and weight-average molecular weights were $\mathrm{M}_{\mathrm{n}}=116 \mathrm{kDa}$ and $\mathrm{M}_{\mathrm{w}}=188 \mathrm{kDa}$ respectively, as measured by Gel Permeation Chromatography. Acetyl tributyl citrate (ATBC, CAS Number 77-90-7) was purchased from sigma Aldrich (France). PLA and ATBC were dried at $80{ }^{\circ} \mathrm{C}$ under vacuum for $12 \mathrm{~h}$. Blending was performed with an internal mixer (Haake Rhecord 9000 ) at $160^{\circ} \mathrm{C}$ and $60 \mathrm{rpm}$ for $15 \mathrm{~min}$. After a subsequent drying step ( $4 \mathrm{~h}$ at $80^{\circ} \mathrm{C}$ under vacuum) bulk samples were obtained. In order to perform WAXS, bulk samples were thermo-molded in films of $1 \mathrm{~mm}$ thickness. For each system, neat PLA were heated during 5 min between two hot plates, and then the obtained films were quickly quenched in cold water. The measure of density leads to a constant value equal to $1.25 \mathrm{~g} / \mathrm{mol}$ independent of the plasticizer content.

\subsection{Electrospinning set-up}

The polymer solutions were prepared in mix solvent of chloroform and acetone (chloroform:acetone $=2: 1$ in volume), both purchased from sigma Aldrich (South Africa). Plasticized and nonplasticized PLA were dissolved in the mix solvent and stirred using a magnetic stir bar at room temperature until homogenization of the solution. The required amounts of polymer were figured out to give a concentration solution of $8 \mathrm{wt} \%$ in PLA. Then, the polymer solution was placed in a horizontally glass pipette with a capillary around $1 \mathrm{~mm}$ diameter. At $5 \mathrm{~cm}$ from the needle, a petri-dish covered by an aluminum foil took place as a collector. The needle and the collector were connected to a high-voltage power supply which can generate a voltage up to $50 \mathrm{kV}$. The electric field applied was $1 \mathrm{kV} \mathrm{cm}-1$. The flow rate was controlled by a pump at $0.04 \mathrm{~mL} \mathrm{~min}^{-1}$. The electrospinning process took place under controlled atmospheric conditions at $25 \pm 2{ }^{\circ} \mathrm{C}$ and $35 \pm 4 \%$ relative humidity. The thickness of the final as-spun fibers mat was less than $1 \mathrm{~mm}$.

\subsection{Scanning electronic microscopy (SEM)}

The morphology of as-spun PLA fibers was investigated by scanning electronic microscopy (LEO 1430VP) after being gold coated during $3 \mathrm{~min}$. The diameter of as-spun fibers was measured with an image analyzer (AxioVision 40LE). For each sample, average fiber diameter and standard deviation were determined from more than 200 measurements of the random fibers. 


\subsection{Wide angle X-ray scattering (WAXS)}

WAXS measurements were performed on a PANalytical X'Pert Pro diffractometer in Bragg-Brentano mode with X'Celerator detector. The generator was set up at $45 \mathrm{kV}$ and $40 \mathrm{~mA}$ and the copper $\mathrm{Cu} \mathrm{K} \alpha$ radiation $(\lambda=1.54 \AA$ ) was selected. The system was equipped with a silicon-made sample holder on a spinner stage PW3064, and a goniometer PW3050/60 system. The silicon holder used is neutral (no diffraction peak) in order to avoid a baseline subtraction step. The distance from the sample to the detector was fixed at $14 \mathrm{~cm}$. The measurements were run at room temperature from $5^{\circ}$ to $45^{\circ}$ at $0.04 \%$ and with a rotational speed equal to one revolution per second. Quenched films and as-spun fibers mats were directly placed on the silicon holder without any preparation. The peak fitting was then performed using the Grafitylabs software after background subtraction to determine the different amorphous contributions by following the method outlined by Stoclet et al. [21].

\subsection{Modulated temperature differential scanning calorimetry (MT- DSC)}

Modulated temperature differential scanning calorimetry (MTDSC) experiments were performed in a DSC Q100 from Thermal Analysis instruments under nitrogen atmosphere $\left(50 \mathrm{~mL} \mathrm{~min}{ }^{-1}\right)$. The calibration in temperature and energy was done using standard of indium, while the calibration of the heat capacity was carried out using sapphire as reference. The MT-DSC experiments were performed in heating from 0 to $200{ }^{\circ} \mathrm{C}$, in "Heat-Only" mode $( \pm 0.318 \mathrm{~K}$ for the oscillation amplitude, $60 \mathrm{~s}$ for the oscillation period and $2 \mathrm{~K} \mathrm{~min}^{-1}$ regarding the heating rate). This mode is recommended to investigate the coupling of different thermal events such as glass transition and cold crystallization without any disturbance caused by instantaneous cooling. The as-spun fibers and bulk samples mass were kept around $5 \mathrm{mg}$. The $\mathrm{Al}$ reference and sample couples, pan and lid, were identical to within $\pm 0.01 \mathrm{mg}$. By MT-DSC, in addition of the modulated heat flow, the apparent specific complex heat capacity $C^{*}$ can be obtained by following the complete deconvolution procedure proposed by Reading and co-authors [35]. Its in-phase component versus temperature $C^{\prime}$ appears as a step, when its out-of-phase component $C^{\prime \prime}$ draws a peak in the glass transition region.

\section{Results and discussion}

From the SEM images shown in Fig. 1, it is evidenced that the process of electrospinning produces PLA fibers with diameters and distributions that are largely independent of the composition. No visible morphological defects such as beads are evident. Neat PLA fibers (Fig. 1A) exhibit an average fiber diameter of $0.80 \mu \mathrm{m}$ with a standard deviation of $0.18 \mu \mathrm{m}$, when plasticized PLA fibers (5\%,10\% and 15\%) display an average fiber diameter and a standard deviation of $0.78 \pm 0.18 \mu \mathrm{m}, 0.69 \pm 0.17 \mu \mathrm{m}$ and $0.81 \pm 0.18 \mu \mathrm{m}$, respectively (Fig. 1(B)-(D)). No visible morphological defects such as beads are evident, and no significant change is observed on the addition of plasticizer. This indicates that the plasticizer has no influence on the fiber diameter during the processing, and that no fiber size variations will interfere in the subsequent analyses of the fibers.

Fig. 2 shows the WAXS analysis for the neat PLA of the quenched films as well as the as-spun fibers. For the quenched film of neat PLA (Fig. 2A), the experimental spectrum displays the usual pattern of a non-crystalline PLA. The fit of the WAXS intensity profile displays three peaks with maxima located at $2 \theta=15.5^{\circ}, 2 \theta=21.3^{\circ}$, and $2 \theta=30.9^{\circ}$. Stoclet et al. [21] have reported three peaks located at $2 \theta=15.0^{\circ}, 2 \theta=21.2^{\circ}$ and $2 \theta=31.0^{\circ}$ for wholly amorphous films, which is in close agreement with our results. The three peaks are characteristics of the chain spacings in amorphous PLA. The components at $2 \theta=15.0^{\circ}$ and $2 \theta=21.2^{\circ}$ arise from two characteristic inter-chain spacings. The third component at $2 \theta=31.0^{\circ}$ is associated to the intra-chain spacing along the chains which refers to the distance of $0.29 \mathrm{~nm}$ between the methyl groups in the 3-fold helices [21]. As shown in Fig. 2B, the fit of the WAXS intensity profile for the as-spun fibers of neat PLA also exhibits three peaks as defined above, but in addition there is a fourth Gaussian peak with a maximum located at $16.0^{\circ}$ (see Table 1 ). The relative area of this fourth peak is only $4 \%$ but its introduction increases the fit correlation (shown in Supplementary information). Moreover, Ma et al. [32] have recently reported the need for the introduction of this fourth peak for non-crystalline electrospun fibers. This fourth peak exhibits a low FWHM equal to $3.0^{\circ}$. That is characteristic of a microstructural organization with an order that is intermediate between the amorphous phase and the crystals. For this reason it has been attributed to the response of the mesophase. The presence of mesophase in electrospun fibers is concordant with the assumption made by Zong et al. [31] that the electrospinning of polylactide can lead to highly oriented chains that do not have enough time to organize into crystals before solidification. It is also worth mentioning that this WAXS profile has also been reported by Stoclet et al. [21] when drawing PLA only $10{ }^{\circ} \mathrm{C}$ above its glass transition.

Fig. 3 displays the WAXS intensity profiles of the quenched films (Fig. 3A) and as-spun fibers (Fig. 3B) that are plasticized with 15\% ATBC. For the quenched films, the WAXS intensity profiles of neat and plasticized PLA are superimposed in the value domain of $2 \theta$ ranging from about 20 to $40^{\circ}$. From this observation, we can deduce that the addition of the plasticizer does not affect the characteristic intra-chain distances. On the other hand, in the value domain of $2 \theta$ ranging from about 10 to $20^{\circ}$, the WAXS intensity profiles are slightly differentiated. Because of the lack of evidence in literature about the fitting procedure for the analysis of plasticized PLA, many fits have been tested, particularly the possibility to fit the domain related to the inter-chain characteristic spacings by one or two contributions. It was, however, impossible to clearly establish the best fit due to the high similarity of the correlation coefficients. As a consequence, the same fitting procedure was used for the quenched film of neat PLA. In this way, only peak I corresponding to the highest inter chain spacing is modified by the addition of plasticizer. This variation may suggest that the addition of plasticizer involves a redistribution of the inter-chain spacing in the amorphous phase.

Fig. 3B shows that, for as-spun fibers, the $2 \theta$ value domain that is characteristic of the intra-chain distances has WAXS intensity profiles that are the same for neat and plasticized PLA. This observation confirms the assumption made for the quenched films. On the other hand, the fitting procedure reveals a significant increase of the correlation coefficient when fitting with only three peaks, i.e., by removing the contribution associated to the presence of the mesophase. Moreover, the position and shape of the two contributions linked to the inter-chain spacing in the amorphous phase are modified compared to neat PLA. The results confirm that the electrospinning of neat PLA induces the creation of a highly ordered non-crystalline microstructure with the presence of mesophase. In the case of plasticized electrospun PLA fibers, the mesophase is no detected. In a general way, the addition of plasticizer changes the environment in the amorphous phase. It does not affect the intra-chain characteristic spacings but induces a strong redistribution of the inter-chain characteristic spacings.

Fig. 4 shows the average heat flow versus temperature obtained from MT-DSC analysis for all the materials. In all cases, three 

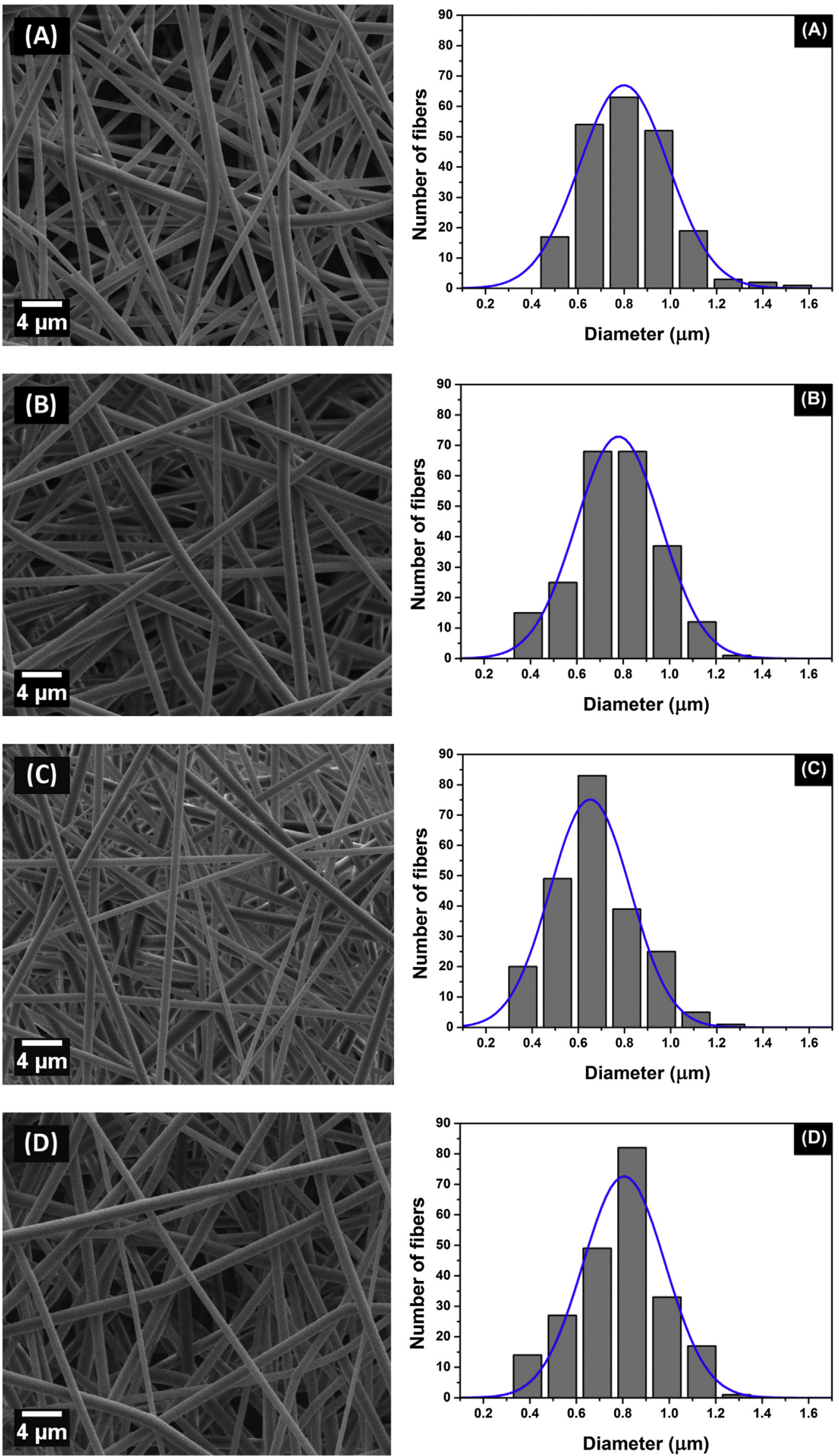

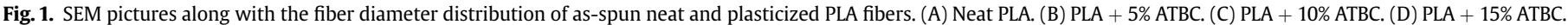



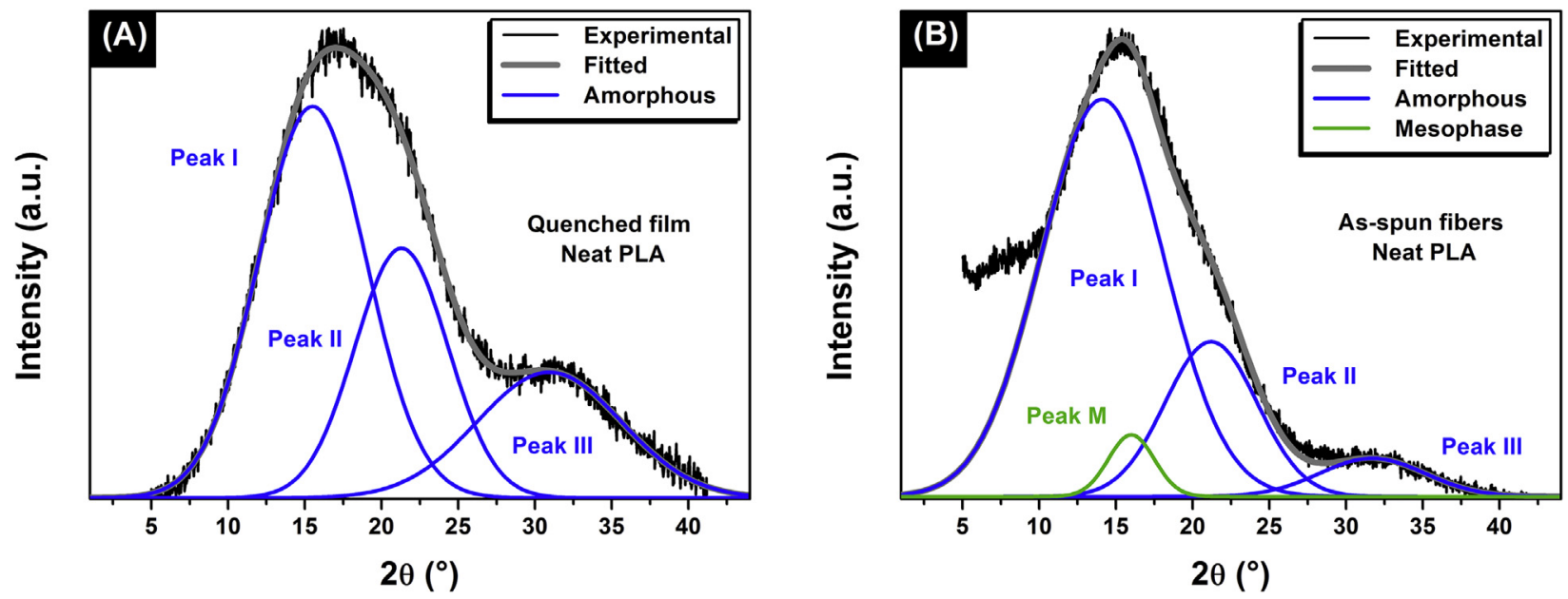

Fig. 2. WAXS intensity profiles and the associated fit of the experimental spectra for: (A) quenched film of neat PLA, (B) as-Spun fibers of neat PLA.

Table 1

Position 20; Full width at mid-height FWHM; and relative area A of the characteristic peaks of the amorphous phase (I; II; III) and the mesophase (M) obtained from the fitting of the WAXS experimental spectra for the as-spun fibers and the quenched films of neat PLA.

\begin{tabular}{|c|c|c|c|c|c|c|c|c|c|c|c|c|}
\hline \multirow[t]{2}{*}{ Neat PLA } & \multicolumn{3}{|l|}{ Peak I } & \multicolumn{3}{|c|}{ Peak II } & \multicolumn{3}{|c|}{ Peak III } & \multicolumn{3}{|c|}{ Peak M } \\
\hline & $\overline{2 \theta\left({ }^{\circ}\right)}$ & FWHM $\left({ }^{\circ}\right)$ & $\overline{A(\%)}$ & $\overline{2 \theta\left({ }^{\circ}\right)}$ & FWHM $\left({ }^{\circ}\right)$ & $\overline{\mathrm{A}(\%)}$ & $\overline{2 \theta\left({ }^{\circ}\right)}$ & FWHM $\left({ }^{\circ}\right)$ & $\overline{\mathrm{A}(\%)}$ & $\overline{2 \theta\left({ }^{\circ}\right)}$ & FWHM $\left({ }^{\circ}\right)$ & $\overline{\mathrm{A}(\%)}$ \\
\hline Quenched films & 15.5 & 7.0 & 51 & 21.3 & 6.1 & 28 & 30.9 & 9.4 & 21 & 1 & 1 & 1 \\
\hline As-spun fibers & 14.1 & 8.0 & 70 & 21.2 & 6.0 & 20 & 31.7 & 6.9 & 6 & 16.0 & 3.0 & 4 \\
\hline
\end{tabular}
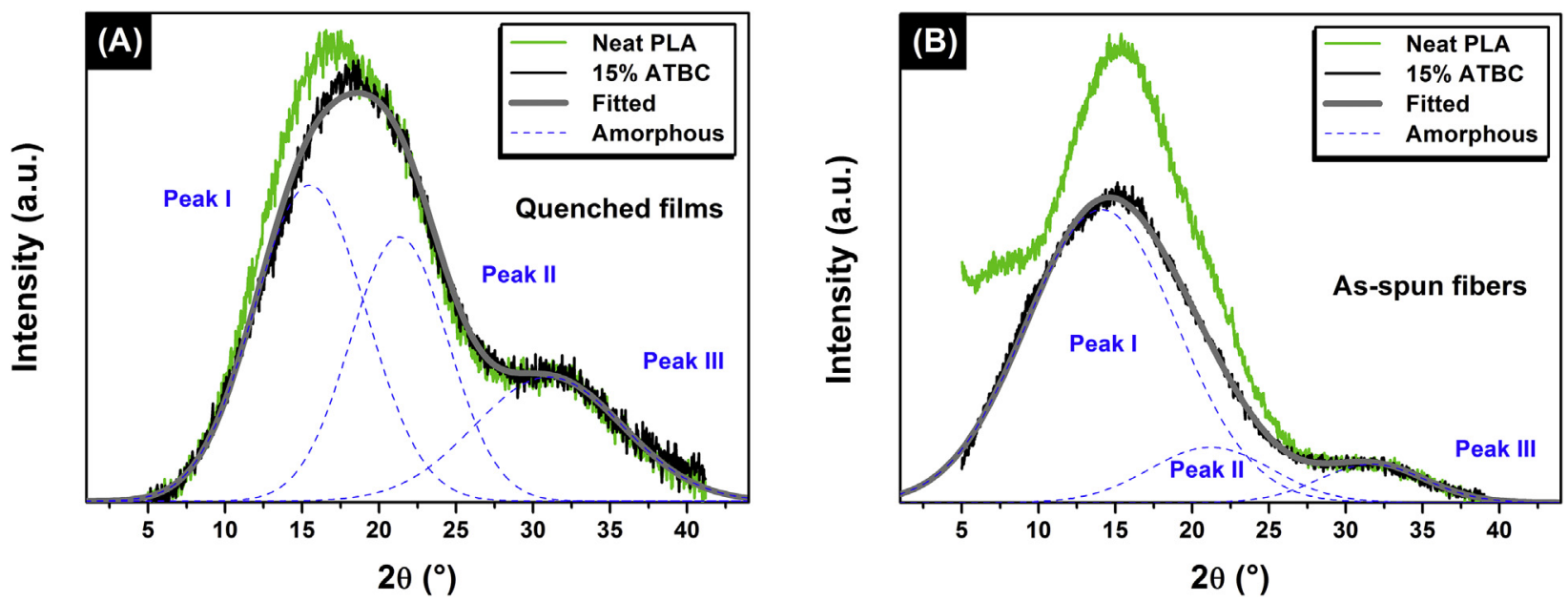

Fig. 3. WAXS intensity profiles for: (A) quenched film of neat PLA (green line) and quenched film of PLA $+15 \%$ ATBC (black line), (B) as-spun fibers of neat PLA (green line) and asspun fibers of PLA $+15 \%$ ATBC (black line). The supposed fits of the experimental spectra for the plasticized materials are displayed in solid gray lines with the individual contributions in dashed blue lines. (For interpretation of the references to color in this figure legend, the reader is referred to the web version of this article.)

thermal events are clearly observed: an endothermic heat flow step characteristic of the glass transition, an exothermic peak due to the cold-crystallization of a part of the amorphous phase and an endothermic event related to the fusion of the crystalline phase. As explained in the introduction, one of the major concerns of the study lies in the creation of non-crystalline samples. It has been verified by the equality between the enthalpy of coldcrystallization and the enthalpy of fusion that no crystals are present prior to the MT-DSC analysis. However, one could immediately see for the as-spun fibers series that the cold-crystallization encroaches on the temperature range of the glass transition. For this reason, the quantitative analysis of both thermal events has been made by separating the events related to the variations of the heat capacity which appear in the reversing heat flow, from the kinetic events which appear in the non-reversing heat flow. An example of this protocol is given in Fig. 5.

In practice, the glass transition temperature has systematically been determined from the reversing heat flow. At the same time, the equality between the enthalpy of cold-crystallization and the enthalpy of fusion has been double checked using the average heat flow signal on the one hand as usually performed from classical DSC, and both the reversing and the non-reversing heat flow signals from MT-DSC on the other hand. The enthalpies of coldcrystallization and fusion are shown in Table 2. These are 

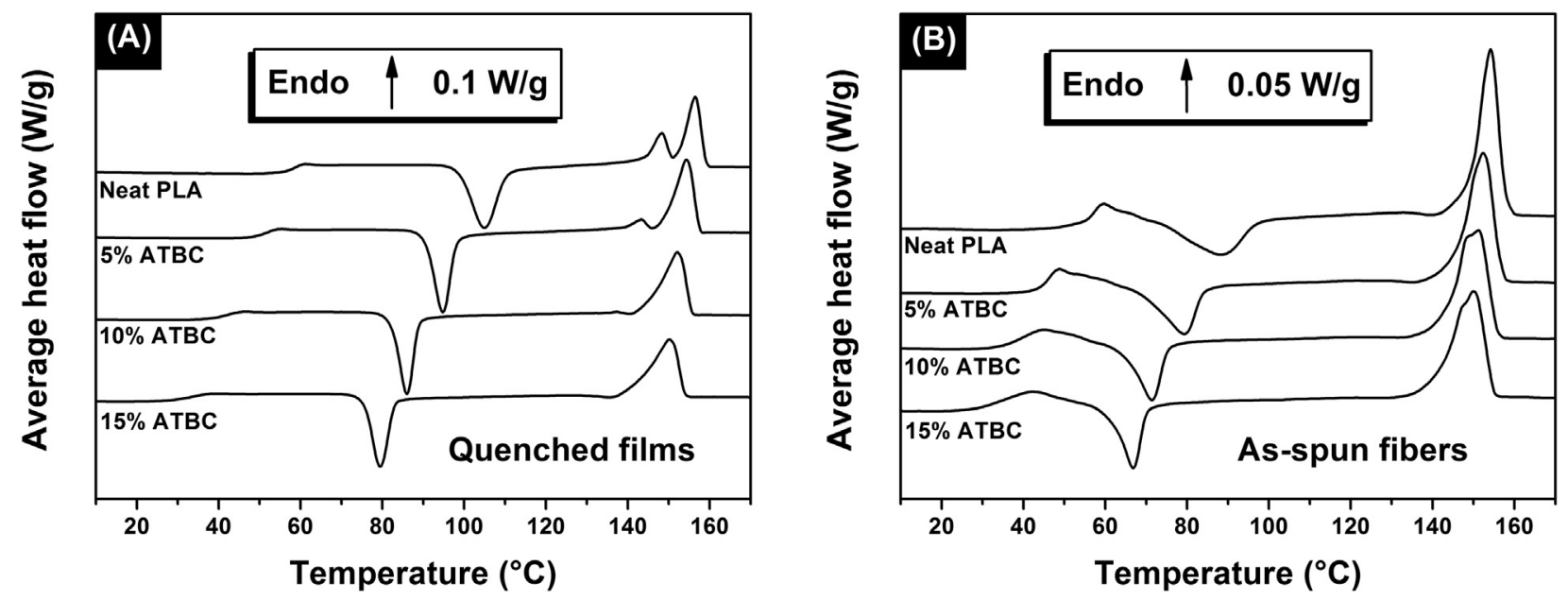

Fig. 4. Average heat flow versus temperature from MT-DSC for: (A) quenched films, (B) as-spun fibers. The curves are shifted for the sake of clarity.
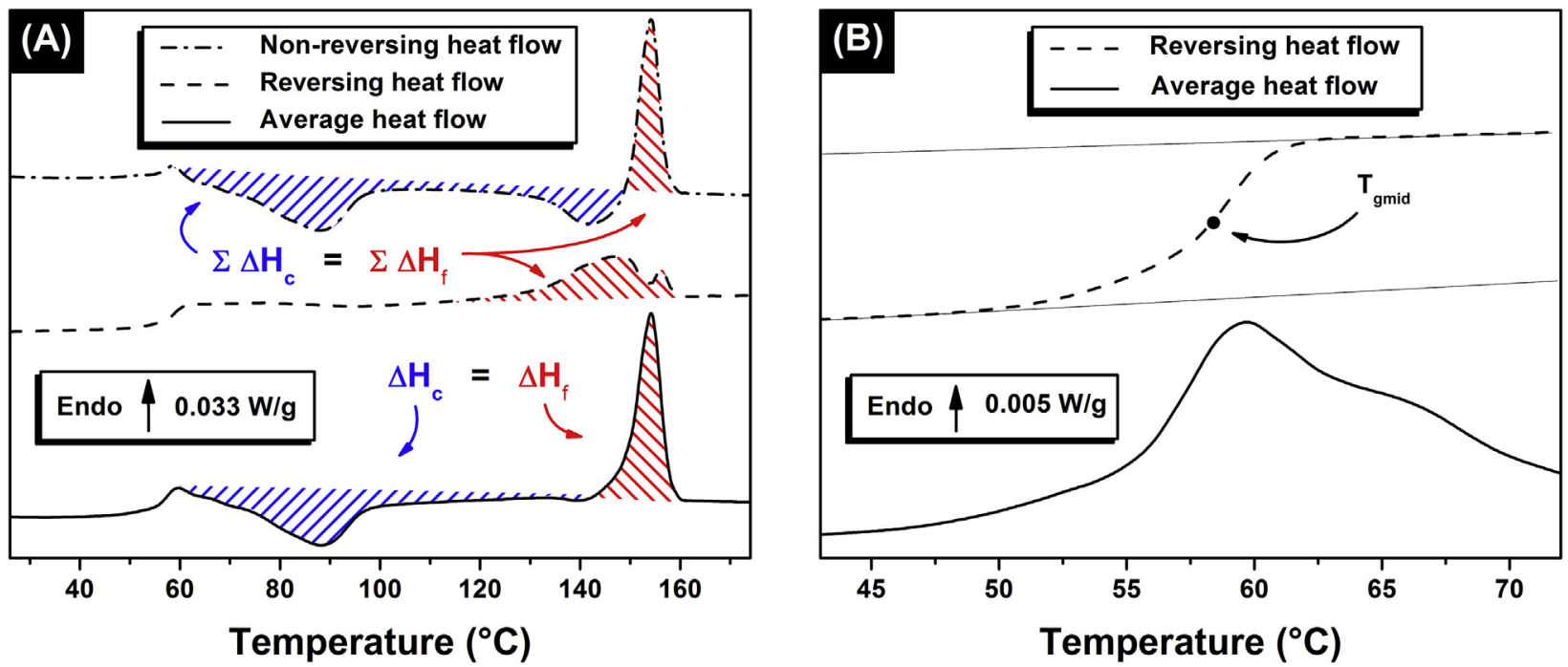

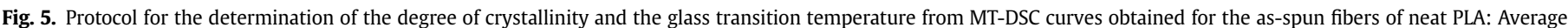

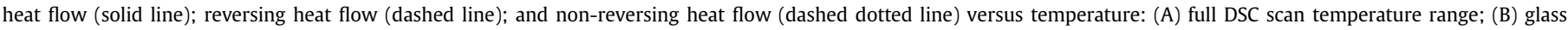
transition domain.

independently equal which proves that the samples are noncrystalline prior to the analysis. This result confirms the previous observations made from WAXS. From the average heat flow curves for quenched neat and plasticized films (Fig. 4A), we observe that when ATBC is introduced in the bulk PLA, both the glass transition and the cold crystallization are shifted to lower temperatures, due to the plasticization. This shift is constant for both thermal events leading to $\mathrm{T}_{\mathrm{c} \max }-\mathrm{T}_{\mathrm{g} \text { mid }}=43{ }^{\circ} \mathrm{C}$ independent of the content of ATBC. By contrast, the peak of fusion changes from a double peak to a single peak which is preceded by an exothermal event. According

Table 2

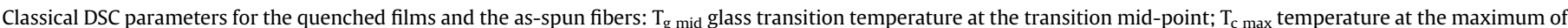

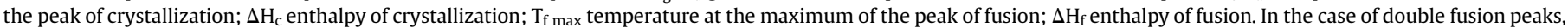

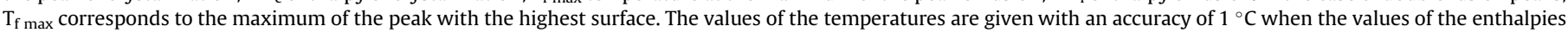
are given with an accuracy of $2 \mathrm{~J} / \mathrm{g}$.

\begin{tabular}{|c|c|c|c|c|c|c|c|}
\hline & ATBC (\%) & $\mathrm{T}_{\mathrm{g} \text { mid }}\left({ }^{\circ} \mathrm{C}\right)$ & $\mathrm{T}_{\mathrm{C} \max }\left({ }^{\circ} \mathrm{C}\right)$ & $\mathrm{T}_{\mathrm{c} \max }-\mathrm{T}_{\mathrm{g} \text { mid }}\left({ }^{\circ} \mathrm{C}\right)$ & $\Delta \mathrm{H}_{\mathrm{c}}(\mathrm{J} / \mathrm{g})$ & $\mathrm{T}_{\mathrm{f} \max }\left({ }^{\circ} \mathrm{C}\right)$ & $\Delta \mathrm{H}_{\mathrm{f}}(\mathrm{J} / \mathrm{g})$ \\
\hline \multirow[t]{4}{*}{ Quenched films } & 0 & 61 & 105 & 44 & 27 & 156 & 27 \\
\hline & 5 & 52 & 95 & 43 & 26 & 154 & 26 \\
\hline & 10 & 45 & 86 & 41 & 23 & 152 & 24 \\
\hline & 15 & 36 & 79 & 43 & 24 & 150 & 24 \\
\hline \multirow{4}{*}{ As-spun fibers } & 0 & 57 & 88 & 31 & 27 & 154 & 28 \\
\hline & 5 & 50 & 79 & 29 & 26 & 152 & 27 \\
\hline & 10 & 41 & 71 & 30 & 24 & 151 & 27 \\
\hline & 15 & 36 & 67 & 31 & 24 & 150 & 27 \\
\hline
\end{tabular}


to many authors [36-38], the double peak is characteristic of the concomitant formation of both highly ordered $\alpha$ crystals and less ordered $\delta$ crystals [39] (also called $\alpha^{\prime}$ crystals [40]). On the other hand, the exothermal event is typically observed when only $\delta$ crystals form during the cold-crystallization [41] and is characteristic of their reorganization in $\alpha$ crystals just prior the fusion $[41,42]$. As a consequence the nature of the crystalline form which is generated during the cold-crystallization changes when the PLA is plasticized. One can also note that the temperature of fusion $T_{f} \max$ decreases slightly with an increase of the ATBC content. This is likely due to the creation of crystals with a lower degree of perfection. The electrospinning of PLA (Fig. 4B) induces a decrease of the glass transition temperature from 61 to $57{ }^{\circ} \mathrm{C}$. A previous study by Zong et al. attributed this behavior to an increase of the surface to volume ratio in electrospun materials having air as a plasticizer. Obviously $\mathrm{T}_{\mathrm{C} \max }-\mathrm{T}_{\mathrm{g} \text { mid }}$ also decreases from $43{ }^{\circ} \mathrm{C}$ to $30{ }^{\circ} \mathrm{C}$. This observation is usual in electrospun fibers $[31,32,43]$ as the orientation of the macromolecules enhances the coldcrystallization which therefore occurs at a lower temperature. In the case of electrospun fibers, Tsuji et al. [43] conclude that the crystallization has been frozen by the fast removal of the solvent from the electrospun fibers. Edwards et al. [44] and Ma et al. [32] even consider that extended polymer chains in electrospun fibers can act as row nuclei during heating just above glass transition. When electrospinning is carried on plasticized PLA, $\mathrm{T}_{\mathrm{g} \text { mid }}$ decreases from $57^{\circ} \mathrm{C}$ to $36^{\circ} \mathrm{C}$ as the content of ATBC increasing from $0 \%$ to $15 \%$ evidencing the plasticizing effect of the ATBC. The decrease of both $\mathrm{T}_{\mathrm{c} \max }$ and $\mathrm{T}_{\mathrm{f} \max }$ previously reported for quenched films is also recorded. Eventually, $\mathrm{T}_{\mathrm{c} \max }-\mathrm{T}_{\mathrm{g} \text { mid }}$ remains equal to $30^{\circ} \mathrm{C}$ which means that in spite of the plasticizer addition, the macromolecules are oriented during the electrospinning. As we discussed before, the plasticizing effect of ATBC is evidenced in both quenched films and electrospun fibers. However one can rightfully question the solubility of ATBC in PLA when the blend is dissolved in a mix of chloroform and acetone. From the Hildebrand solubility theory $[45,46]$, the small molecules in the electrospinning solution (chloroform, acetone and ATBC) have closely matching parameters; [18.4 $\left.\left.(\mathrm{MJ} \mathrm{m})^{-3}\right)^{0.5}\right]$ for ATBC, [19.0 $\left.\left(\mathrm{MJ} \mathrm{m}^{-3}\right)^{0.5}\right]$ for chloroform, [20.0 $\left(\mathrm{MJ} \mathrm{m} \mathrm{m}^{-3}\right)^{0.5}$ ] for acetone. On the other hand, the Hildebrand solubility parameter of PLA is equal to $\left[21.9\left(\mathrm{MJ} \mathrm{m}^{-3}\right)^{0.5}\right]$. Consequently there is a chance that the ATBC will be partially carried along by the solvent during the evaporation. In Fig. 6 , the $T_{g}$ mid is given as a function of the ATBC weight content for both quenched films and electrospun fibers. Clearly the trend is independent on the process, as the $T_{g}$ mid decreases similarly with an increasing content of ATBC. The expected variations of the $T_{g}$ mid with the content of ATBC according to Fox law have also been included in the figure. To do this, it has been foreseen that the tendency will shift whether we consider $T_{g}$ mid of quenched films or as-spun fibers as the reference $\mathrm{T}_{\mathrm{g} \text { mid }}$ for neat PLA. In both cases the variations of the glass transition temperature roughly follow Fox's law. This proves that the ATBC remains trapped in PLA during the evaporation of the solvent, likely because of its lower vapor pressure at ambient temperature, its higher molecular weight and its higher boiling point compare to chloroform and acetone.

To confirm the structural modifications revealed by WAXS, it is interesting to investigate whether plasticization and electrospinning cause changes affecting the glass transition profile. Fig. 7A shows the average heat flow and the non-reversing heat flow for the quenched film of neat PLA in the glass transition domain. The interest in using the non-reversing heat flow in this case is to highlight the possible kinetic events occurring simultaneously with the glass transition. For example, in Fig. 7A, a peak is recorded on the non-reversing heat flow signal, which is related to the existence of an endothermic event. Classically, due to the glassy character of

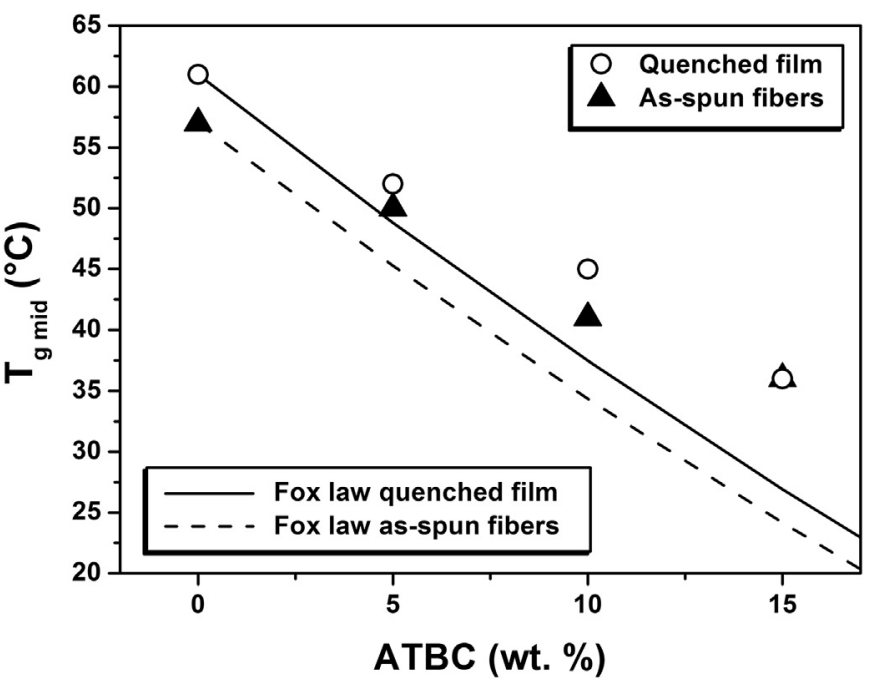

Fig. 6. $T_{g}$ mid versus ATBC weight content for all materials. The solid curve corresponds to the Fox law by considering the $T_{g}$ value of the quenched film of neat PLA. The dashed curve corresponds to the Fox law by considering the $T_{g}$ value of the as-spun fibers of neat PLA.

PLA at ambient temperature, this peak might be attributed in to physical aging. For the PLA plasticized with $15 \%$ ATBC, the profile presented in Fig. 7B is similar but the glass transition as well as the peak in the non-reversing heat flow signal are significantly broadened. This observation is consistent with previous observations on plasticized polylactide $[11,33]$ and is related to an increase of the relaxation temperature distribution induced by the plasticizer addition. We cannot be definitive concerning the nature of this peak. Nevertheless, its enlargement with plasticization coincides with the increase of the dynamic heterogeneity in the amorphous phase [11]. Typically this heterogeneity reflects in the structural relaxation $[11,47]$ so the initial hypothesis of physical aging is reinforced. In Fig. 7C, two thermal events can be distinguished. The first appears at the beginning of the glass transition, similar to the peaks observed in Fig. 7A and B. It is reasonable to consider that it is related to the same thermal event, most likely the recovery of structural relaxation. The second peak occurs just at the junction between the glass transition and the cold-crystallization. Ma et al. [32] in their DSC analyses on free-end fibers, also observed a shouldering between the glass transition and the coldcrystallization but they did not ascribed it to any given thermal event. In our study, this behavior is only observed for the as-spun fibers of neat PLA so the existence of the second peak could be related to the presence of mesophase previously revealed by WAXS Indeed it has been reported that the "melting" of the mesophase in oriented PLA often occurs in the glass transition temperature range when its thermal stability is low [18,48]. According to Lv et al. [48], when the formation of the mesophase is not followed by a subsequent crystallization (which provides a good representation of the microstructure of as-spun fibers), the molecular ordering induced by the process is completely destroyed above $T_{g}$ due to the conformational rearrangements of the macromolecules that become possible with the sudden gain of molecular mobility. When electrospinning is carried on plasticized PLA, as shown in Fig. 7D, the two separated thermal events observed for as-spun fibers of neat PLA are replaced by a broad peak covering the entire temperature range. In these conditions, it is impossible to definitively assert whether or not this peak constitutes the signature of only one thermal event. It is clear, however, that the ATBC strongly impacts the organization of the macromolecules. 

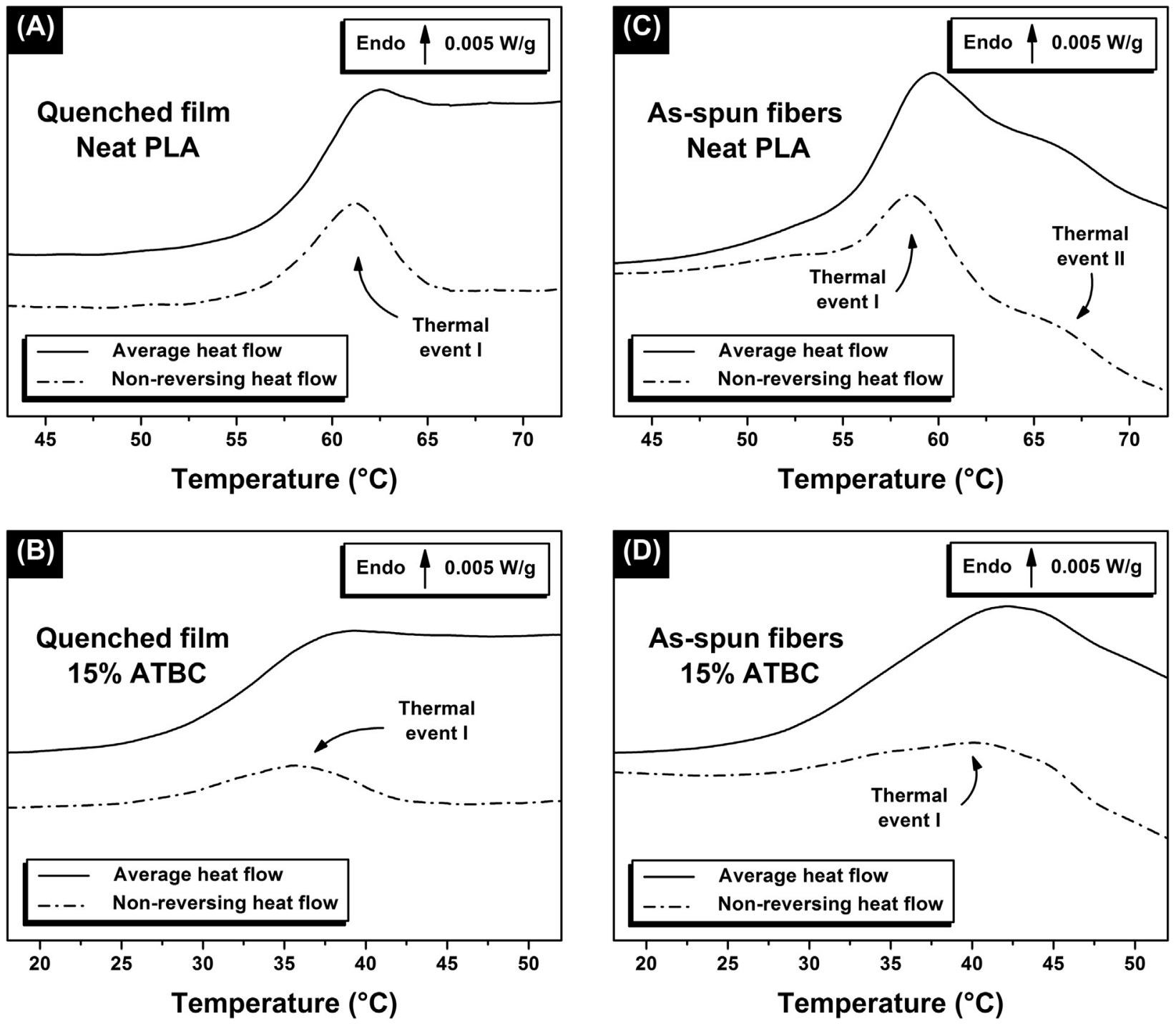

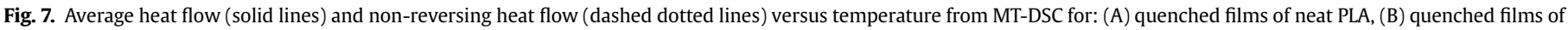
PLA $+15 \%$ ATBC, (C) as-spun fibers of neat PLA, (D) as-spun fibers of PLA $+15 \%$ ATBC.

Fig. 8 shows the $C^{\prime}$ and $C^{\prime \prime}$ signals for neat PLA and blends with $15 \%$ ATBC for the as-spun fibers and the bulk samples. From these two components, as explained elsewhere [13], it is possible to extract the dynamic glass transition temperature $T_{\alpha}$ that corresponds to the maximum of the $C^{\prime \prime}$ peak, the heat capacity at constant pressure extrapolated to $T_{\alpha}$ in the glassy $C_{p}$ glass and liquid $C_{p}$ liquid states, as well as the mean temperature fluctuation associated with the glass transition $\delta T$ that allow the calculation of the cooperativity length $\xi_{T \alpha}$. The density of the amorphous phase is also needed for the calculation of the $\xi_{T \alpha}$ and has been approximated as being equal to the density of the material, i.e., equal to $1.25 \mathrm{~g} / \mathrm{mol}$ due to the obvious majority of the amorphous phase in all the samples. All these relaxation parameter values are presented in Table 3.

As expected, the plasticizer addition in bulk PLA from $0 \%$ to $15 \%$ weight content induces a decrease of $T_{\alpha}$ from $62{ }^{\circ} \mathrm{C}$ to $36^{\circ} \mathrm{C}$. It also increases $\delta T$ from $3.1{ }^{\circ} \mathrm{C}$ to $5.5^{\circ} \mathrm{C}$ without clear modification of the heat capacity step $\Delta C^{\prime}$ which leads $\xi_{T \alpha}$ to decrease from $2.8 \mathrm{~nm}$ down to $2.0 \mathrm{~nm}$. The values of cooperativity lengths agree with those reported by Dobircau et al. [11] on PLA plasticized with ATBC, as well as those reported by Delpouve et al. regarding neat PLA bulk
[13]. When the neat PLA undergoes electrospinning, $T_{\alpha}$ decreases similarly to $T_{\mathrm{g}}$ from $62{ }^{\circ} \mathrm{C}$ to $59^{\circ} \mathrm{C}$. An increase of $\Delta C^{\prime}$ from 0.49 to $0.57 \mathrm{~J} \mathrm{~g}^{-1} \mathrm{~K}^{-1}$ is also recorded. However, the usually high uncertainty around the values of the heat capacity step does not allow for the distinguishing of whether this variation is significant or not. On the other hand, the $C^{\prime \prime}$ peak is obviously narrower for the as-spun fibers than the bulk. Consequently, the as-spun fibers present an average fluctuation temperature of $2.4{ }^{\circ} \mathrm{C}$ against $3.1^{\circ} \mathrm{C}$ for the bulk and the cooperativity length in the as-spun fibers reaches $3.6 \mathrm{~nm}$ against $2.8 \mathrm{~nm}$ in the bulk, which corresponds approximatively to an increase of the cooperativity length of around 30\%. Such an increase of cooperativity induced by the process is not usual and rarely mentioned in literature, so it will get further consideration in the following paragraphs. Finally one can observe that the plasticized materials exhibit similar values of relaxation parameters whether they are electrospun or not. In other words, the electrospinning has no effect on the alpha relaxation of plasticized polylactide.

As mentioned in the introduction, the cooperativity length is dependent on both the temperature and the structural organization into the material. In the present study, the cooperativity length has 

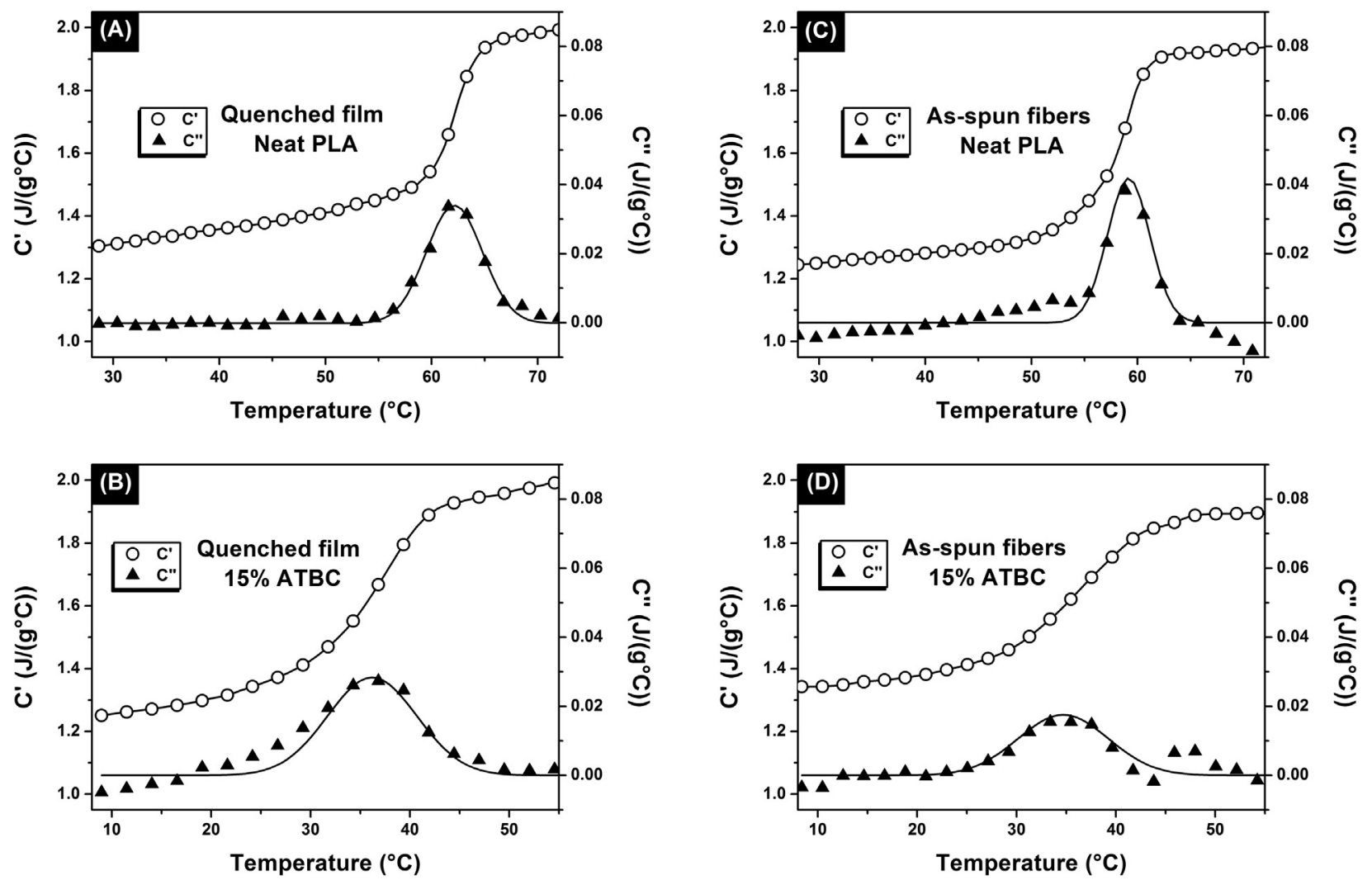

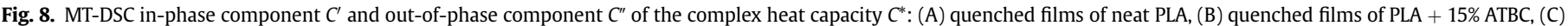
as-spun fibers of neat PLA, (D) as-spun fibers of PLA $+15 \%$ ATBC.

been calculated for each material at the dynamic glass transition temperature in order to limit the observed variations to structural causes. Fig. 9 aims at picturing the structural dependence of the cooperativity resulting from the external and internal hindrances imposed on the material by focusing on four representative systems. In the bulk amorphous PLA (system 1), the macromolecules arrange themselves into random coil, leading to a cooperativity length close to $3 \mathrm{~nm}$ which is in accordance with reported values for the characteristic length of the glass transition related to dynamic heterogeneity $[3,49,50]$. It is often reported in the literature that the relaxation time distribution broadens when the amorphous phase becomes constrained $[13,47]$. Since the electrospinning induces the orientation of the macromolecules of PLA in the amorphous phase (system 2), one might have expected that the cooperativity at the glass transition will decrease. On the contrary the molecular motions at the glass transition are more cooperative. To explain this result, we should first consider that despite the

Table 3

Modulated Temperature DSC parameters for the quenched films and the as-spun fibers: $T_{\alpha}$ dynamic glass transition temperature, $\Delta C^{\prime}$ heat capacity step from the in-phase component; $\delta T$ mean temperature fluctuation related to the glass transition, $\xi_{T \alpha}$ cooperativity length at the dynamic glass transition temperature.

\begin{tabular}{lcllll}
\hline & $\operatorname{ATBC}(\%)$ & $\Delta \mathrm{C}^{\prime}\left(\mathrm{J} \mathrm{g}^{-1} \mathrm{~K}^{-1}\right)$ & $\mathrm{T}_{\alpha}\left({ }^{\circ} \mathrm{C}\right)$ & $\delta \mathrm{T}\left({ }^{\circ} \mathrm{C}\right)$ & $\xi_{\mathrm{T} \alpha}(\mathrm{nm})$ \\
\hline Quenched films & 0 & $0.49 \pm 0.05$ & $62 \pm 1$ & $3.1 \pm 0.2$ & $2.8 \pm 0.3$ \\
& 5 & $0.44 \pm 0.05$ & $55 \pm 1$ & $4.1 \pm 0.2$ & $2.5 \pm 0.2$ \\
& 10 & $0.49 \pm 0.05$ & $46 \pm 1$ & $4.7 \pm 0.3$ & $2.1 \pm 0.3$ \\
As-spun fibers & 15 & $0.51 \pm 0.05$ & $36 \pm 1$ & $5.3 \pm 0.3$ & $2.0 \pm 0.3$ \\
& 0 & $0.57 \pm 0.05$ & $59 \pm 1$ & $2.4 \pm 0.1$ & $3.6 \pm 0.3$ \\
& 5 & $0.50 \pm 0.05$ & $51 \pm 1$ & $4.0 \pm 0.2$ & $2.6 \pm 0.2$ \\
& 10 & $0.51 \pm 0.05$ & $42 \pm 1$ & $4.7 \pm 0.3$ & $2.2 \pm 0.2$ \\
& 15 & $0.45 \pm 0.05$ & $35 \pm 1$ & $5.4 \pm 0.3$ & $2.0 \pm 0.2$ \\
\hline
\end{tabular}

orientation of the macromolecules, the material is non-crystalline which means that the amorphous phase is not confined in any way. That makes a big difference compare to semi-crystalline drawn materials that typically exhibit lower cooperativity motions at the glass transition $[5,14]$. In this latter case, the decrease of cooperativity induced by the drawing should not be attributed to the induced orientation of the macromolecules but to the presence of crystallites confining the amorphous phase. It is also interesting to notice that the increase of cooperativity in an initially bulk amorphous material is often related to the same cause, i.e. the creation of nano-domains playing the role of anchoring points between the macromolecules $[10,51]$. In our case, we can reasonably assume that the highly cohesive mesophase plays this role by increasing the level of inter-molecular interactions, thus leading to the global increase of the cooperativity length. The opposite effect occurs when adding ATBC to the bulk PLA (system 3). Although the action of the plasticizer still deserves more investigations, it is revealed from our WAXS measurements that the increase of the dynamic heterogeneities which leads to the decrease of the average cooperativity length is associated to a redistribution of the interchain distances. This is consistent with the assumption that the cooperativity length is correlated with the nature and the number of inter-chain interactions [52]. In regard to this hypothesis, the decrease of the cooperativity length could be interpreted as the consequence of inter-chain bond breaking. Finally, although MTDSC results suggest that the macromolecules are oriented in the electrospun plasticized materials (system 4), the cooperativity at the glass transition remains unchanged before and after electrospinning. We assume that the changes in molecular dynamics induced by the plasticizer addition are prevalent over the structural reorganization induced by electrospinning, and that the plasticization is not favorable to the formation of the mesophase. 

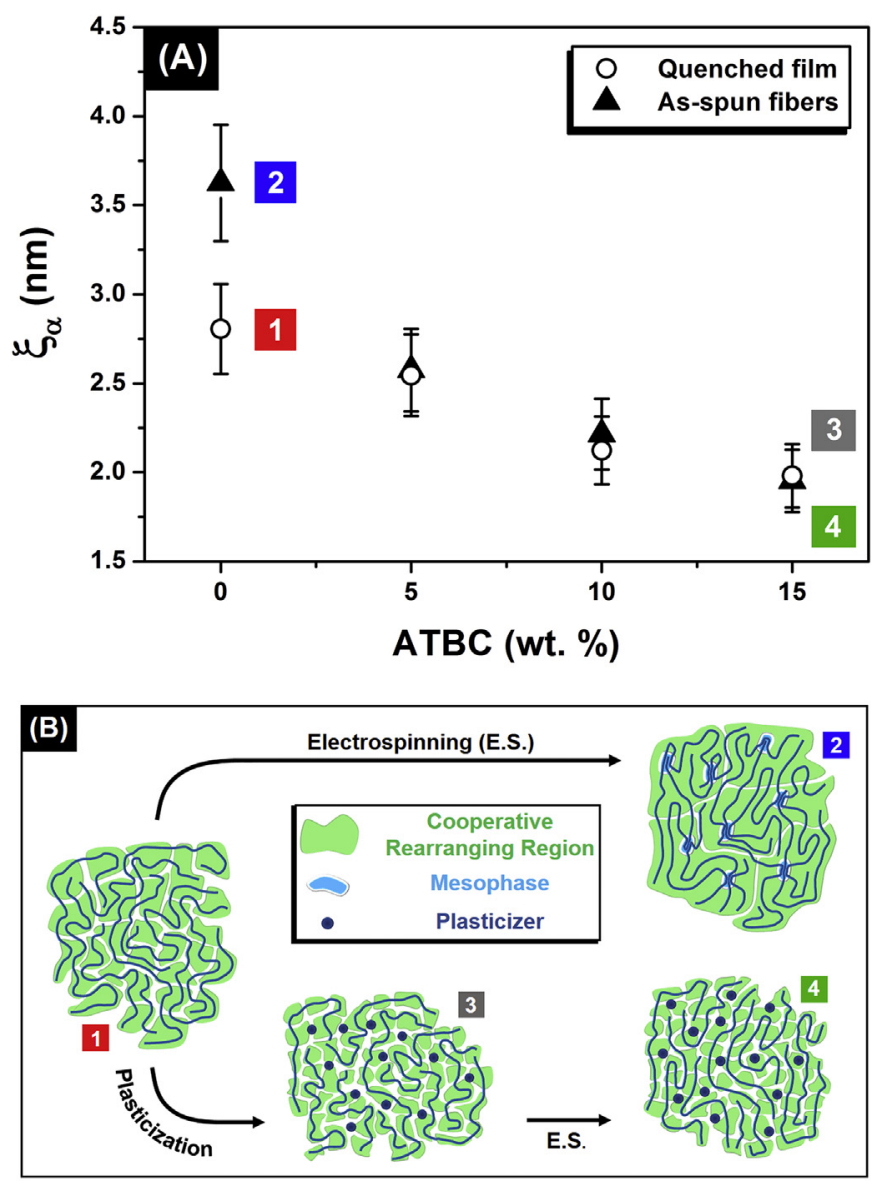

Fig. 9. Structural dependence of the cooperativity at the glass transition: (A) Cooperativity length versus ATBC content in quenched films and as-spun fibers, (B) schematic view of the macromolecule organization for representative systems.

\section{Conclusion}

The microstructure induced by the electrospinning of polylactide depends both on the level of orientation of the macromolecules and on the necessary time for the macromolecules to reorganize in crystals. In this study, a highly ordered but noncrystalline microstructure has been generated, exhibiting about $4 \%$ of mesophase. In comparison to bulk polylactide, the alpha relaxation of electrospun PLA is more cooperative. Since the cooperative motions at the glass transition are often related to the aptitude of the polymeric chains to connect by physical bonds, it is assumed that the mesophase plays the role of anchoring points between macromolecules due to its high cohesiveness. The plasticization of polylactide cancels any difference of cooperativity length between bulk and as-spun fibers. Both exhibit a decrease of cooperativity with the content of plasticizer. We assume that the plasticization induces strong modifications in the inter-chain characteristic spacing and frustrates the creation of physical interactions between macromolecules. This effect prevails over the changes in the macromolecule organization that are induced by electrospinning. It is also worth mentioning that the electrospinning of plasticized PLA is successful.

\section{Acknowledgments}

The authors would like to gratefully thank the University of Rouen for the financial support for Xavier Monnier: "International Mobility Help".

\section{Appendix A. Supplementary information}

Supplementary data related to this article can be found at http:// dx.doi.org/10.1016/j.polymer.2015.07.047.

\section{References}

[1] G. Adam, J.H. Gibbs, On the temperature dependence of cooperative relaxation properties in glass-forming liquids, J. Chem. Phys. 43 (2004) 139-146, http:// dx.doi.org/10.1063/1.1696442.

[2] E. Donth, The size of cooperatively rearranging regions at the glass transition, J. Non-Cryst. Solids 53 (1982) 325-330, http://dx.doi.org/10.1016/00223093(82)90089-8.

[3] E. Hempel, G. Hempel, A. Hensel, C. Schick, E. Donth, Characteristic length of dynamic glass transition near $T_{\mathrm{g}}$ for a wide assortment of glass-forming substances, J. Phys. Chem. B 104 (2000) 2460-2466, http://dx.doi.org/ 10.1021/jp991153f.

[4] Y.Z. Chua, G. Schulz, E. Shoifet, H. Huth, R. Zorn, J.W.P. Scmelzer, et al., Glass transition cooperativity from broad band heat capacity spectroscopy, Colloid Polym. Sci. 292 (2014) 1893-1904, http://dx.doi.org/10.1007/s00396-0143280-2.

[5] F. Hamonic, D. Prevosto, E. Dargent, A. Saiter, Contribution of chain alignment and crystallization in the evolution of cooperativity in drawn polymers, $\begin{array}{llll}\text { Polymer } & 55 \quad \text { (2014) 2882-2889, http://dx.doi.org/10.1016/ }\end{array}$ j.polymer.2014.04.030.

[6] R. Casalini, D. Fragiadakis, C.M. Roland, Dynamic correlation length scales under isochronal conditions, J. Chem. Phys. 142 (2015) 064504, http:// dx.doi.org/10.1063/1.4907371.

[7] T.A. Tran, S. Saïd, Y. Grohens, Nanoscale characteristic length at the glass transition in confined syndiotactic poly(methyl methacrylate), Macromolecules 38 (2005) 3867-3871, http://dx.doi.org/10.1021/ma0487296.

[8] K. Arabeche, L. Delbreilh, R. Adhikari, G.H. Michler, A. Hiltner, E. Baer, et al., Study of the cooperativity at the glass transition temperature in PC/PMMA multilayered films: influence of thickness reduction from macro- to nanoscale, Polymer $53 \quad$ (2012) 1355-1361, http://dx.doi.org/10.1016/ j.polymer.2012.01.045.

[9] G.P. Kar, P. Xavier, S. Bose, Polymer-grafted multiwall carbon nanotubes functionalized by nitrene chemistry: effect on cooperativity and phase miscibility, Phys. Chem. Chem. Phys. PCCP 16 (2014) 17811-17821, http:// dx.doi.org/10.1039/c4cp01594k.

[10] A. Saiter, D. Prevosto, E. Passaglia, H. Couderc, L. Delbreilh, J.M. Saiter, Cooperativity length scale in nanocomposites: interfacial and confinement effects, Phys. Rev. E 88 (2013) 042605, http://dx.doi.org/10.1103/ PhysRevE.88.042605.

[11] L. Dobircau, N. Delpouve, R. Herbinet, S. Domenek, L. Le Pluart L. Delbreilh, et al., Molecular mobility and physical ageing of plasticized poly(lactide), Polym. Eng. Sci. 55 (2015) 858-865, http://dx.doi.org/10.1002/pen.23952.

[12] J. Dobbertin, A. Hensel, C. Schick, Dielectric spectroscopy and calorimetry in the glass transition region of semi-crystalline poly(ethylene terephthalate), J. Therm. Anal. 47 (1996) 1027-1040, http://dx.doi.org/10.1007/BF01979446.

[13] N. Delpouve, A. Saiter, J.F. Mano, E. Dargent, Cooperative rearranging region size in semi-crystalline poly(L-lactic acid), Polymer 49 (2008) 3130-3135, http://dx.doi.org/10.1016/j.polymer.2008.04.045.

[14] Y. Furushima, K. Ishikiriyama, T. Higashioji, The characteristic length of cooperative rearranging region for uniaxial drawn poly(ethylene terephthalate) films, Polymer 54 (2013) 4078-4084, http://dx.doi.org/10.1016/ j.polymer.2013.06.030.

[15] H. Bai, C. Huang, H. Xiu, Q. Zhang, Q. Fu, Enhancing mechanical performance of polylactide by tailoring crystal morphology and lamellae orientation with the aid of nucleating agent, Polymer 55 (2014) 6924-6934, http://dx.doi.org/ 10.1016/j.polymer.2014.10.059.

[16] W. Chen, D. Reichert, T. Miyoshi, Helical jump motions of poly(L-lactic acid) chains in the $\alpha$ phase as revealed by solid-state NMR, J. Phys. Chem. B 119 (2015) 4552-4563, http://dx.doi.org/10.1021/acs.jpcb.5b00694.

[17] N. Delpouve, L. Delbreilh, G. Stoclet, A. Saiter, E. Dargent, Structural dependence of the molecular mobility in the amorphous fractions of polylactide, Macromolecules 47 (2014) 5186-5197, http://dx.doi.org/10.1021/ ma500839p.

[18] G. Stoclet, R. Seguela, J.-M. Lefebvre, C. Rochas, New insights on the straininduced mesophase of poly(D,L-lactide): in situ WAXS and DSC study of the thermo-mechanical stability, Macromolecules 43 (2010) 7228-7237, http:// dx.doi.org/10.1021/ma101430c.

[19] K. Wasanasuk, K. Tashiro, Structural regularization in the crystallization process from the glass or melt of poly(L-lactic acid) viewed from the temperature-dependent and time-resolved measurements of FTIR and wideangle/small-angle X-ray scatterings, Macromolecules 44 (2011) 9650-9660, http://dx.doi.org/10.1021/ma2017666.

[20] Y. Wang, H. Zhang, M. Li, W. Cao, C. Liu, C. Shen, Orientation and structural development of semicrystalline poly(lactic acid) under uniaxial drawing assessed by infrared spectroscopy and X-ray diffraction, Polym. Test. 41 (2015) 163-171, http://dx.doi.org/10.1016/j.polymertesting.2014.11.010.

[21] G. Stoclet, R. Seguela, J.M. Lefebvre, S. Elkoun, C. Vanmansart, Strain-induced molecular ordering in polylactide upon uniaxial stretching. Macromolecules 
43 (2010) 1488-1498, http://dx.doi.org/10.1021/ma9024366.

[22] L. Liu, Y. Ren, Y. Li, Y. Liang, Effects of hard and soft components on the structure formation, crystallization behavior and mechanical properties of electrospun poly(L-lactic acid) nanofibers, Polymer 54 (2013) 5250-5256, http://dx.doi.org/10.1016/j.polymer.2013.07.046.

[23] G.M. Bayley, P.E. Mallon, Porous microfibers by the electrospinning of amphiphilic graft copolymer solutions with multi-walled carbon nanotubes, Polymer $53 \quad$ (2012) 5523-5539, http://dx.doi.org/10.1016/ j.polymer.2012.08.058.

[24] N. Bhardwaj, S.C. Kundu, Electrospinning: a fascinating fiber fabrication technique, Biotechnol. Adv. 28 (2010) 325-347, http://dx.doi.org/10.1016/ j.biotechadv.2010.01.004.

[25] R. Neppalli, V. Causin, E.M. Benetti, S.S. Ray, A. Esposito, S. Wanjale, et al., Polystyrene $/ \mathrm{TiO}_{2}$ composite electrospun fibers as fillers for poly(butylene succinate-co-adipate): structure, morphology and properties, Eur. Polym. J. 50 (2014) 78-86, http://dx.doi.org/10.1016/j.eurpolymj.2013.11.002.

[26] G. Liao, S. Jiang, X. Xu, Y. Ke, Electrospun aligned PLLA/PCL/HA composite fibrous membranes and their in vitro degradation behaviors, Mater. Lett. 82 (2012) 159-162, http://dx.doi.org/10.1016/j.matlet.2012.05.085.

[27] I. Keun Kwon, S. Kidoaki, T. Matsuda, Electrospun nano- to microfiber fabrics made of biodegradable copolyesters: structural characteristics, mechanical properties and cell adhesion potential, Biomaterials 26 (2005) 3929-3939, http://dx.doi.org/10.1016/j.biomaterials.2004.10.007.

[28] K. Yoon, K. Kim, X. Wang, D. Fang, B.S. Hsiao, B. Chu, High flux ultrafiltration membranes based on electrospun nanofibrous PAN scaffolds and chitosan coating, Polymer 47 (2006) 2434-2441, http://dx.doi.org/10.1016/ j.polymer.2006.01.042.

[29] W. Serrano, A. Meléndez, I. Ramos, N.J. Pinto, Electrospun composite poly(lactic acid)/polyaniline nanofibers from low concentrations in $\mathrm{CHCl}_{3}$ : making a biocompatible polyester electro-active, Polymer 55 (2014) 5727-5733. http://dx.doi.org/10.1016/j.polymer.2014.09.015.

[30] B. Na, P. Zhang, R. Lv, R. Tian, Y. Ju, Q. Liu, Effect of ionic liquids on the morphology and mesophase formation of electrospun polylactide nanofibers, Polymer 65 (2015) 55-62, http://dx.doi.org/10.1016/j.polymer.2015.03.077.

[31] X. Zong, K. Kim, D. Fang, S. Ran, B.S. Hsiao, B. Chu, Structure and process relationship of electrospun bioabsorbable nanofiber membranes, Polymer 43 (2002) 4403-4412, http://dx.doi.org/10.1016/S0032-3861(02)00275-6.

[32] Q. Ma, M. Pyda, B. Mao, P. Cebe, Relationship between the rigid amorphous phase and mesophase in electrospun fibers, Polymer 54 (2013) 2544-2554, http://dx.doi.org/10.1016/j.polymer.2013.03.019.

[33] C. Courgneau, S. Domenek, A. Guinault, L. Avérous, V. Ducruet, Analysis of the structure-properties relationships of different multiphase systems based on plasticized poly(lactic acid), J. Polym. Environ. 19 (2011) 362-371, http:// dx.doi.org/10.1007/s10924-011-0285-5.

[34] F. Hassouna, J.-M. Raquez, F. Addiego, V. Toniazzo, P. Dubois, D. Ruch, New development on plasticized poly(lactide): chemical grafting of citrate on PLA by reactive extrusion, Eur. Polym. J. 48 (2012) 404-415, http://dx.doi.org/ 10.1016/j.eurpolymj.2011.12.001.

[35] A.A. Lacey, D.M. Price, M. Reading, Theory and practice of modulated temperature differential scanning calorimetry, Modul. Temp. Differ. Scanning Calorim., Springer (2006) 1-81.

[36] M. Yasuniwa, S. Tsubakihara, K. Iura, Y. Ono, Y. Dan, K. Takahashi, Crystallization behavior of poly(L-lactic acid), Polymer 47 (2006) 7554-7563, http:// dx.doi.org/10.1016/j.polymer.2006.08.054.

37] P. Pan, W. Kai, B. Zhu, T. Dong, Y. Inoue, Polymorphous crystallization and multiple melting behavior of poly(L-lactide): molecular weight dependence

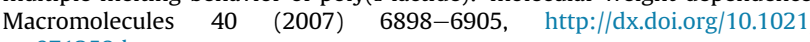
ma071258d.

[38] M.L. Di Lorenzo, Calorimetric analysis of the multiple melting behavior of poly(L-lactic acid), J. Appl. Polym. Sci. 100 (2006) 3145-3151, http:// dx.doi.org/10.1002/app.23136.

[39] K. Wasanasuk, K. Tashiro, Crystal structure and disorder in poly(t-lactic acid) $\delta$ form ( $\alpha^{\prime}$ form) and the phase transition mechanism to the ordered $\alpha$ form Polymer 52 (2011) 6097-6109, http://dx.doi.org/10.1016 j.polymer.2011.10.046.

[40] C.-Y, Chen, C.-F. Yang, U.-S. Jeng, A.-C. Su, Intrinsic metastability of the $\alpha^{\prime}$ phase and its partial transformation into $\alpha$ crystals during isothermal coldcrystallization of poly(L-lactide), Macromolecules 47 (2014) 5144-5151, http://dx.doi.org/10.1021/ma501167e.

[41] J. Zhang, K. Tashiro, H. Tsuji, A.J. Domb, Disorder-to-order phase transition and multiple melting behavior of poly (L-lactide) investigated by simultaneous measurements of WAXD and DSC, Macromolecules 41 (2008) 1352-1357.

[42] T. Kawai, N. Rahman, G. Matsuba, K. Nishida, T. Kanaya, M. Nakano, et al. Crystallization and melting behavior of poly (L-lactic acid), Macromolecules 40 (2007) 9463-9469, http://dx.doi.org/10.1021/ma070082c.

[43] H. Tsuji, M. Nakano, M. Hashimoto, K. Takashima, S. Katsura, A. Mizuno, Electrospinning of poly(lactic acid) stereocomplex nanofibers, Biomacromolecules 7 (2006) 3316-3320, http://dx.doi.org/10.1021/bm060786e.

[44] M.D. Edwards, G.R. Mitchell, S.D. Mohan, R.H. Olley, Development of orientation during electrospinning of fibres of poly( $\varepsilon$-caprolactone), Eur. Polym. J. 46 (2010) 1175-1183, http://dx.doi.org/10.1016/j.eurpolymj.2010.03.017.

[45] A. Ruellan, V. Ducruet, S. Domenek, CHAPTER 5 Plasticization Polylactide 2014 (Chapter 5).

[46] R.S. Ruoff, D.S. Tse, R. Malhotra, D.C. Lorents, Solubility of fullerene (C60) in a variety of solvents, J. Phys. Chem. 97 (1993) 3379-3383, http://dx.doi.org/ $10.1021 / \mathrm{j} 100115 \mathrm{a} 049$.

[47] N.M. Alves, J.F. Mano, E. Balaguer, J.M. Meseguer Dueñas, J.L. Gómez Ribelles, Glass transition and structural relaxation in semi-crystalline poly(ethylene terephthalate): a DSC study, Polymer 43 (2002) 4111-4122, http://dx.doi.org/ 10.1016/S0032-3861(02)00236-7.

[48] R. Lv, B. Na, N. Tian, S. Zou, Z. Li, S. Jiang, Mesophase formation and its thermal transition in the stretched glassy polylactide revealed by infrared spectroscopy, Polymer 52 (2011) 4979-4984, http://dx.doi.org/10.1016 j.polymer.2011.08.023.

[49] D. Fragiadakis, P. Pissis, L. Bokobza, Glass transition and molecular dynamic in poly(dimethylsiloxane)/silica nanocomposites, Polymer 46 (2005) 6001-6008, http://dx.doi.org/10.1016/j.polymer.2005.05.080.

[50] J. Koppensteiner, W. Schranz, M.A. Carpenter, Revealing the pure confinement effect in glass-forming liquids by dynamic mechanical analysis, Phys. Rev. B 81 (2010) 024202, http://dx.doi.org/10.1103/PhysRevB.81.024202.

[51] C.E. Corcione, A. Maffezzoli, Glass transition in thermosetting claynanocomposite polyurethanes, Thermochim. Acta 485 (2009) 43-48, http:/ dx.doi.org/10.1016/j.tca.2008.12.009.

[52] M. Nakanishi, R. Nozaki, Model of the cooperative rearranging region for polyhydric alcohols, Phys. Rev. E 84 (2011), http://dx.doi.org/10.1103/ PhysRevE.84.011503. 